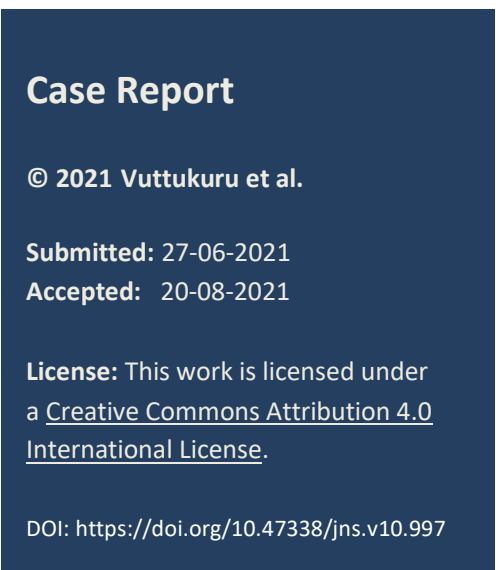

\title{
Cystic hygroma and esophageal atresia with tracheoesophageal fistula: Is there a
} genetic association?

\section{Sravanthi Vuttukuru, Nitin J Peters, * Shivani Dogra, Ram Samujh}

Department of Pediatric Surgery, Post Graduate Institute of Medical Education and Research (PGIMER) Chandigarh, India

Correspondence*: Dr. Nitin J Peters, Department of Pediatric Surgery, Post Graduate Institute of Medical Education and Research (PGIMER) Chandigarh, India. E-mail: nitinjamespeters@yahoo.com

\section{KEYWORDS \\ Tracheoesophageal fistula, Cystic hygroma, \\ Fox gene complex

\begin{abstract}
Background: Tracheoesophageal fistula (TEF) is associated with many other congenital anomalies like cardiac, renal, and vertebral, but the association with cystic hygroma is very rare.

Case Presentation: We report a neonate, antenatally diagnosed with cystic hygroma of the neck and incidentally diagnosed to have TEF. The baby was operated on after adequate stabilization and the cystic hygroma was managed with injection sclerotherapy. The genetic analysis for the FOX genes complex has been done in this case and the results showed no association between the two.
\end{abstract}

Conclusion: There is a need for future studies to find out if the association between cystic hygroma and TEF is by chance or if any embryological or genetic cause can be attributed to it.

\section{INTRODUCTION}

Esophageal atresia and tracheoesophageal fistula (TEF) has an incidence of 1 in 3500 live births and is associated with several congenital anomalies including cardiac and renal.[1] Almost 50\% of the babies may have either syndromic or sporadic associations like Down syndrome and VACTERL.[2] Few associations are rarer such as with duodenal atresia, esophageal lung, and vascular rings.[3,4] Its association with cystic hygroma is not reported to the best of our knowledge. Herein we report a case of esophageal atresia with TEF associated with cystic hygroma of the neck.

\section{CASE REPORT}

The index case was antenatally diagnosed to have a lymphatic malformation in the neck at 31 weeks of gestation. A $2.4 \mathrm{~kg}$ male baby was delivered at 40 weeks of gestation by LSCS delivery (in view of nonprogress of labour). The baby cried immediately after birth, was pink and active with an APGAR of 8 and 9. A $8 * 7 \mathrm{~cm}$ soft cystic transilluminant lesion, arose from the left lateral side of the neck. The morphology of the lesion was consistent with cystic hygroma (Fig. 1). The baby also had excessive frothing and drooling of saliva. On attempting nasogastric feeding (NG) tube placement, there was resistance and X-ray showed coiling of NG tube suggestive of esophageal atresia and TEF. Ultrasonography of neck suggested a $7 * 3$ $\mathrm{cm}$ multicystic septated anechoic lesion with areas of soft tissue in the left cervical region suggestive of a cystic hygroma.

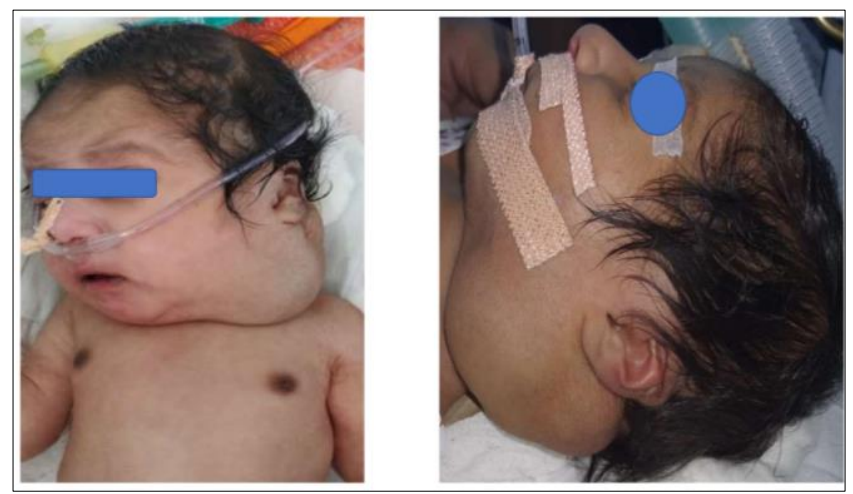

Figure 1: Cystic hygroma on the left side of neck, soft cystic lesion of size $8 * 7 \mathrm{~cm}$

Surgery for TEF was performed by open right posterolateral thoracotomy. The upper and lower pouch were moderately developed with a wide fistula and a gap of $2 \mathrm{~cm}$. Ligation of the fistula and end to end anastomosis of the esophagus was done. The postoperative period was uneventful and NG feeds were started after 24 hours. On postoperative day 7 , a 
contrast esophagogram was done which showed a good caliber esophageal anastomosis and no evidence of leak.

During the hospital stay, the baby received sclerotherapy twice for cystic hygroma, on day 1 of life and on postoperative day 16 . Injection bleomycin at a dose of $0.3 \mathrm{IU} / \mathrm{kg}$ was used for sclerotherapy. There was a marked response with a decrease in size of the swelling. A total of five sessions of sclerotherapy were given with good clinical results (Fig. 2). On a 1-year follow-up, the child is doing well and gaining weight adequately.

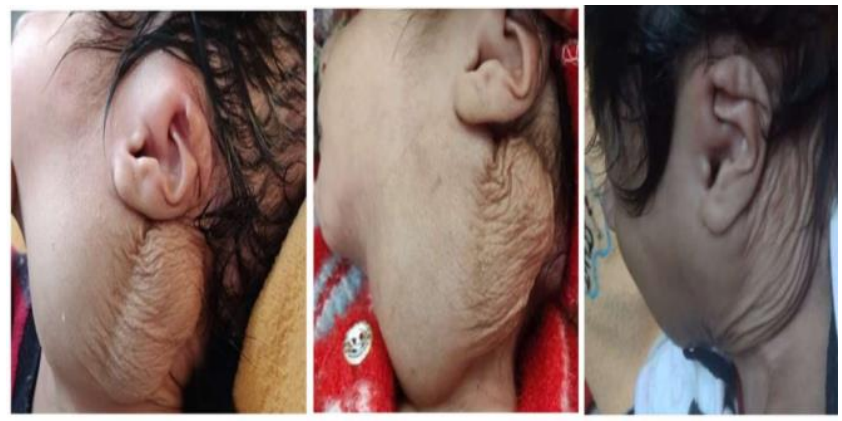

Figure 2: Sequence of pictures showing reduction in size of the lesion

\section{DISCUSSION}

Tracheoesophageal fistula is a common major congenital malformation and is associated with several anomalies. TEF is commonly associated with the VACTERL sequence (24-60\%).[5] CHARGE syndrome, trisomy 18, trisomy 21, and DiGeorge syndrome are other associations. Recent research shows a phenotype similar to VACTERL association could be attributed to micro-deletions of FOX gene cluster on chromosome 16p24.1, comprising of 4 genes, FOXF1, MTHFSD, FOXC2 and FOXL1.[1] Patients with these deletions have gastrointestinal defects like TEF with esophageal atresia, duodenal and ileal atresia along with alveolar capillary dysplasia.

Cystic hygroma $(\mathrm{CH})$ or hygroma cysticum coli, is a benign, congenital macrocystic lymphatic malformation, usually presenting within 3 years of age. Approximately $50-60 \%$ are seen in infancy and $90 \%$ by 2 years of age.[6] They can occur anywhere in the body, but the most common site is the left cervical region. The etiology is not well known but may be associated with maternal alcohol intake and viral infection like parvo virus.[6] It is usually associated with Down syndrome, Turner syndrome, Noonan syndrome and other trisomies and fetal hydrops.[7] Garabedian et al. in their study established the occurrence of cystic hygroma due to a deletion of $16 q 24.1$ with haploinsufficiency of FOXF1 and FOXC2 genes.[8] Various case reports have been published on the rare associations of cystic hygroma, but its association with TEF has not been reported.
Microdeletions of FOX cluster at $16 \mathrm{p} 24.1$, result in alveolar capillary dysplasia with misalignment of pulmonary veins, a lethal disorder. It is also associated with anomalies of different other organ systems and may resemble VACTERL association. Patients with deletions spanning the entire FOX cluster (FOXF1, MTHFSD, FOXC2 and FOXL1) also have congenital heart defects, urinary tract malformations, vertebral or axial malformations and single umbilical artery. Mutations in FOXF1 are responsible for gastrointestinal malformations, whereas mutations in FOXFC2 are responsible for lymphovascular anomalies.[1] Targeted Gene sequencing has been done in our patient, to identify the mutations in FOX genes. DNA extracted from the blood was used to perform the targeted gene capture, and the GATX framework has been used for the identification of the variants. The clinically relevant mutations were annotated using the known variants in the literature and relevant databases, however, this interpretation showed no pathologic variants causative of the reported phenotype.

Management of a neonate with $\mathrm{TEF}$ intraoperatively can be challenging for an anaesthesiologist. Intubation of the fistula can be troublesome as the child does not maintain saturation adequately. One lung being constantly retracted to visualise the operative field, maintaining ventilation can be difficult and the assisting surgeon is frequently asked to release the lung intermittently. Presence of $\mathrm{CH}$, worsens the management of TEF on table. Large lump in the neck, restricts the neck movements and prevents adequate extension of the neck, for intubation. To overcome this problem, C-Mac ${ }^{\circledR}$ was used to intubate the neonate. Intraoral extension of $\mathrm{CH}$, can obscure the visualisation of vocal cords. Intra-thoracic extension can cause compression over the trachea. USG in the index case showed well-defined lesions and did not need further investigations. Sedation should be used cautiously, as it can cause airway compromise, due to loss of muscle tone. So, tracheostomy set should be ready at the time of intubation.[9] Luckily, in our subject, though the $\mathrm{CH}$ was big, it did not have an intraoral or thoracic extension.

To conclude, tracheoesophageal fistula is associated with many other congenital anomalies, but association with cystic hygroma is very rare. Further studies are needed to know if the association between cystic hygroma and TEF is by chance or if any embryological or genetic cause can be attributed to it.

\footnotetext{
Acknowledgements: Nil

Conflict of Interest: None.

Source of Support: Nil

Consent to Publication: Author(s) declared taking informed written consent for the publication of clinical photographs/material (if any used), from the legal guardian of the patient with an understanding
} 
that every effort will be made to conceal the identity of the patient, however it cannot be guaranteed.

\section{REFERENCES}

1. Shaw-Smith C. Genetic factors in esophageal atresia, tracheo-esophageal fistula and the VACTERL association: roles for FOXF1 and the 16q24.1 FOX transcription factor gene cluster, and review of the literature. Eur J Med Genet. 2010; 53:6-13.

2. Scott DA. Esophageal Atresia / Tracheoesophageal Fistula Overview. 2009 Mar 12 [Updated 2018 Sep 20]. In: Adam MP AH, Pagon RA, et al., editors. GeneReviews ${ }^{\circledR}$ [Internet]. Seattle (WA): University of Washington, Seattle; 1993-2021.

3. Escobar MA Jr, Welke KF, Holland RM, Caty MG. Esophageal atresia associated with a rare vascular ring and esophageal duplication diverticulum: a case report and review of the literature. J Pediatr Surg. 2012; 47:1926-9.

4. Panda S, Srinivas M, Bajpai M, Sharma N, Singh A, Baidya D, et al. Esophageal atresia, duodenal atresia, and imperforate anus: Triple atresia. J Clin Neonatol. 2015; 4:188-92.

5. de Jong EM, Felix JF, Deurloo JA, van Dooren MF, Aronson DC, Torfs CP, et al. Non-VACTERL-type
Author Contributions: Author(s) declared to fulfil authorship criteria as devised by ICMJE and approved the final version.

anomalies are frequent in patients with esophageal atresia/tracheo-esophageal fistula and full or partial VACTERL association. Birth Defects Res A Clin Mol Teratol. 2008; 82:92-7.

6. Gnanavel A DP, Vikram T. Cystic hygroma- A case report and its embryological basis. Anat Physiol. 2015; 5:169. doi:10.4172/2161-0940.1000169.

7. Chen YN, Chen CP, Lin CJ, Chen SW. Prenatal ultrasound evaluation and outcome of pregnancy with fetal cystic hygromas and lymphangiomas. J Med Ultrasound. 2017; 25:12-5.

8. Garabedian MJ, Wallerstein D, Medina N, Byrne J, Wallerstein RJ. Prenatal diagnosis of cystic hygroma related to a deletion of 16q24.1 with haploinsufficiency of FOXF1 and FOXC2 genes. Case Rep Genet. 2012; 2012:490408.

9. Rao KS, Shenoy T. Anesthetic management of a large cystic hygroma in a newborn. Anesth Essays Res. 2015; 9:270-2. 